\title{
Safety and efficacy of antihypertensive therapy with add-on angiotensin II type 1 receptor blocker after successful coronary stent implantation
}

\author{
Makoto Sugihara $^{1}$, Shin-ichiro Miura ${ }^{1,2}$, Yosuke Takamiya ${ }^{1}$, Yoshihiro Kiya ${ }^{1}$, Tadaaki Arimura ${ }^{1}$, Atsushi Iwata ${ }^{1}$,
} Akira Kawamura $^{1}$, Hiroaki Nishikawa ${ }^{1}$, Yoshinari Uehara ${ }^{1}$ and Keijiro Saku ${ }^{1}$

This study was performed to evaluate the safety and efficacy of additional antihypertensive therapy with angiotensin II type 1 receptor blocker (ARB; olmesartan or valsartan) after successful stent implantation in patients with coronary artery disease (CAD). Fifty patients with CAD after successful stent implantation were included in this study. They were divided into an ARB group, which initially received olmesartan $\left(n=20,14 \pm 8 \mathrm{mg} \mathrm{day}^{-1}\right)$ or valsartan $\left(n=20,60 \pm 23 \mathrm{mg} \mathrm{day}^{-1}\right)$ immediately after stent implantation, and a non-ARB group $(n=10)$ according to their blood pressure (BP). Follow-up coronary angiography, measurement of BP and blood sampling were performed before (at baseline) and 6-8 months after stent implantation (at follow-up). There were no significant differences in the baseline characteristics between the groups, except for BP. Although there were no changes in \% diameter restenosis between the groups, the BP level in the ARB group at follow-up showed a significant reduction $(125 \pm 12 / 69 \pm 9 \mathrm{~mm} \mathrm{Hg})$ and reached the target BP. There were no critical adverse effects in the ARB group throughout the study period. In addition, serum high-sensitive C-reactive protein (hs-CRP) and pentraxin 3 were significantly decreased in the ARB group but not in the non-ARB group. Although olmesartan and valsartan induced similar BP-lowering effects, olmesartan but not valsartan induced a significant decrease in hs-CRP, but did not increase serum uric acid. In conclusion, antihypertensive therapy with add-on low-dose ARB after stent implantation was safe and achieved the target BP. In particular, olmesartan had an anti-inflammatory effect.

Hypertension Research (2009) 32, 625-630; doi:10.1038/hr.2009.66; published online 22 May 2009

Keywords: angiotensin II type 1 receptor blocker; coronary artery disease; high-sensitive C-reactive protein; olmesartan; valsartan

\section{INTRODUCTION}

Angiotensin II (Ang II) plays an important role as a major regulator of blood pressure (BP), electrolyte balance and endocrine function related to cardiovascular homeostasis as well as disease. ${ }^{1}$ Ang II receptor blockers (ARBs) are highly selective for the Ang II type 1 $\left(\mathrm{AT}_{1}\right)$ receptor, which is a member of the G-protein-coupled receptor superfamily, and block the diverse effects of Ang II. $^{2}$

The Guidelines for the Management of Hypertension from the Japanese Society of Hypertension 2009 recommend BP goals of $<130$ / $80 \mathrm{~mm} \mathrm{Hg}$ for patients with diabetes, chronic kidney disease or a history of myocardial infarction (MI). ${ }^{3}$ As BP is not adequately controlled in two-thirds of patients, intensive therapy is needed to achieve the control of BP. On the other hand, it has been suggested that intensive BP-lowering might result in impaired coronary flow and induce cardiovascular events. ${ }^{4}$ Messerli et al. ${ }^{5}$ reported that the relationship between BP and the primary outcome, all-cause death, and total MI was J-shaped, particularly for diastolic BP at 119/ $84 \mathrm{~mm} \mathrm{Hg}$ (systolic (S) BP/diastolic (D) BP mm Hg). The Hisayama study reported that the general population with optimal BP $(<120 /$ $80 \mathrm{~mm} \mathrm{Hg}$ ) had a low risk for coronary artery disease (CAD). ${ }^{6}$ Until now, there has been no clear evidence regarding whether the lowering of BP is safe and beneficial in reducing cardiovascular events, including coronary restenosis.

Inflammation plays a pathological role in the progression of atherosclerosis. Pentraxin 3 (PTX3) and its short form, C-reactive protein (CRP), are inflammation markers. PTX3 is expressed in advanced atherosclerotic lesions. ${ }^{7}$ Treatment with ARBs leads to a decrease in inflammation and adhesion molecules, such as CRP, ${ }^{8}$ intercellular adhesion molecule-1, chemokines, E-selectin and monocyte chemotactic protein (MCP)-1. ${ }^{9,10}$ In addition, monocyte and endothelial cell activation markers were significantly decreased in patients with type 2 diabetes after treatment with valsartan. ${ }^{11}$ In addition, valsartan has been shown to be effective at preventing coronary restenosis in an open-label clinical study (Val-PREST). ${ }^{12}$ Although the ARB olmesartan may have the strongest depressor effect, ${ }^{13}$ there are no reports regarding whether all ARBs have the

${ }^{1}$ Department of Cardiology, Fukuoka University School of Medicine, Fukuoka, Japan and ${ }^{2}$ Department of Molecular Cardiology, Lerner Research Institute, Cleveland Clinic Foundation, Cleveland, OH, USA

Correspondence: Dr S-i Miura, Department of Cardiology, Fukuoka University School of Medicine, 7-45-1 Nanakuma, Jonan-ku, Fukuoka 814-0180, Japan. E-mail: miuras@cis.fukuoka-u.ac.jp

Received 30 January 2009; revised 24 March 2009; accepted 9 April 2009; published online 22 May 2009 
same effects for the treatment of CAD. Thus, ARBs may have novel effects that contribute to anti-inflammatory activity through the downregulation of adhesion molecules and chemokines, which are pleiotropic effects in addition to any BP-lowering effect.

Therefore, this study was performed to evaluate the safety and efficacy of antihypertensive therapy with add-on ARB (olmesartan or valsartan) after successful stent implantation in patients with CAD. We may identify critical factors, such as inflammation makers, in the abilities of ARBs to prevent coronary restenosis with optimal BP.

\section{METHODS}

\section{Patients}

The participants included 50 patients who did not receive ARB before coronary stent implantation and who were successfully implanted with a drug-eluting stent (DES) or bare-metal stent (BMS) at Fukuoka University Hospital from October 2006 to December 2007. If the BP level was $\geqslant 130 / 80 \mathrm{~mm} \mathrm{Hg}$, the patient initially received ARBs beginning the day after stent implantation (ARB group, olmesartan in 20 cases (average dose, $14 \pm 8 \mathrm{mg} \mathrm{day}^{-1}$ ) or valsartan in 20 cases $\left.\left(60 \pm 23 \mathrm{mg} \mathrm{day}^{-1}\right)\right)$. Ten age-, sex- and body mass index-matched patients who did not receive ARB before or after stent implantation (BP $<130 / 80 \mathrm{~mm} \mathrm{Hg}$ ) were also enrolled as a non-ARB group. Follow-up coronary angiography was performed after stenting (6-8 months; mean period, $210 \pm 42$ days). All patients received aspirin and ticlopidine or clopidogrel throughout the study period.

Patients did not have vascular disease (aortitis treated by prednisolone) or hepatic dysfunction (viral or nonviral transaminases more than three times the normal value). Patients with low-density lipoprotein-cholesterol (LDL-C) $\geqslant 140 \mathrm{mg}$ per $100 \mathrm{ml}$ or triglyceride $\geqslant 150 \mathrm{mg}$ per $100 \mathrm{ml}$ were diagnosed as dyslipidemia. BP was measured in the right arm after a 5 -min resting period, and the average of 3 consecutive BP measurements was used for analysis. Patients with SBP or DBP $\geqslant 140$ or $\geqslant 90 \mathrm{~mm} \mathrm{Hg}$ or who were under antihypertensive treatment were considered to have hypertension (HT). Patients who were being treated for diabetes mellitus (DM) or who had symptoms of DM and a fasting blood glucose concentration $\geqslant 126 \mathrm{mg}$ per $100 \mathrm{ml}$ were considered to have DM. Otherwise, the results of a 75-g oral glucose tolerance test were used to diagnose DM. The ethics committee of Fukuoka University Hospital approved this study and written informed consent was obtained from each patient.

\section{Quantitative coronary angiography}

Quantitative coronary angiography was performed on all qualifying angiograms at the angiographic core laboratory at Fukuoka University Hospital using CMS (MEDIS, Leiden, The Netherlands) immediately before and after the procedure (pre) and at follow-up. Quantitative coronary angiography analysis was performed in the in-stent area, the overlapped site and the in-segment area, which included the stented segment as well as the margins $(5 \mathrm{~mm})$ proximal and distal to the stent. Restenosis was defined as $>50 \%$ diameter stenosis at follow-up angiography.

\section{Blood sample}

Blood sampling was performed before stent implantation and at follow-up. We determined serum sodium $(\mathrm{Na})$ and potassium $(\mathrm{K})$, the plasma lipid profile (LDL-C, high-density lipoprotein-cholesterol and triglyceride), hemoglobin Alc (HbAlc), uric acid (UA), PTX3, high-sensitive CRP (hs-CRP), adiponectin, MCP-1 and regulated on activation, normal T-cell-expressed and secreted (RANTES). The concentrations of adiponectin, MCP-1 and RANTES and PTX3 in plasma were determined in duplicate by specific enzyme immunoassays according to the manufacturer's instructions (R\&D Systems, Minneapolis, MN, USA and Perseus Proteomics Inc., Tokyo, Japan). At our laboratory, the intra- and inter-assay coefficients of variation for these parameters were each $<5 \%$.

\section{Calculation of estimated glomerular filtration rate}

Estimated glomerular filtration rate was determined using the abbreviated equation that the Japanese Society of Nephrology modified for the Japanese on the basis of the Modification of Diet in Renal Disease study; ${ }^{14} 0.741 \times 175 \times$ (age $($ years $))^{-0.203} \times(\text { serum } \mathrm{Cr}(\mathrm{mg} \text { per } 100 \mathrm{ml}))^{-1.154} \times(0.742$ if female $)$.

\section{Statistical analysis}

Statistical analysis was performed using the Stat View statistical software package (Stat View 5; SAS Institute Inc., Cary, NC, USA) at Fukuoka University (Fukuoka, Japan). Dates are shown as the mean \pm s.d. Categorical variables were compared between groups by $\chi^{2}$ analysis or Fisher's exact test. The differences in continuous variables between groups were examined by Student's $t$-test or Wilcoxon's rank-sum test. Differences were considered to be statistically significant when the $P$-values were $<0.05$.

\section{RESULTS}

\section{Baseline patient characteristics}

Baseline patient characteristics are shown in Table 1. SBP in the ARB group was significantly higher than that in the non-ARB group. Several coronary risk factors such as sex, smoking, DM, HT and dyslipidemia were similar in the non-ARB and ARB groups and in the olmesartan and valsartan groups. There was no significant difference in the use of medications, such as $\beta$-blockers, calcium-channel blockers, statin and nicorandil, between the groups.

\section{Angiographic characteristics at baseline and follow-up}

Among the angiographic characteristics at baseline, there were no significant differences regarding vessel disease, target vessels, lesion complexity or mean diameter and length of the stented segment between the non-ARB and ARB groups or the olmesartan and valsartan groups (Table 2). There was also no significant difference in the type of stent.

\section{Table 1 Baseline patient characteristics}

\begin{tabular}{|c|c|c|c|}
\hline & \multirow[b]{2}{*}{$\begin{array}{c}\text { Non-ARB } \\
(\mathrm{n}=10)\end{array}$} & \multicolumn{2}{|c|}{$A R B$} \\
\hline & & $\begin{array}{c}\text { Olmesartan } \\
(\mathrm{n}=20)\end{array}$ & $\begin{array}{c}\text { Valsartan } \\
(\mathrm{n}=20)\end{array}$ \\
\hline Age (year) & $67 \pm 14$ & $63 \pm 11$ & $64 \pm 12$ \\
\hline Male (\%) & 80 & 80 & 90 \\
\hline $\mathrm{BMI}\left(\mathrm{kg} \mathrm{m}^{-2}\right)$ & $24 \pm 3$ & $25 \pm 3$ & $24 \pm 3$ \\
\hline Smoking (\%) & 50 & 70 & 65 \\
\hline Diabetes mellitus (\%) & 40 & 50 & 30 \\
\hline Hypertension (\%) & 40 & 80 & 70 \\
\hline Dyslipidemia (\%) & 80 & 90 & 80 \\
\hline $\operatorname{ACS}(\%)$ & 10 & 20 & 15 \\
\hline $\mathrm{SBP}(\mathrm{mm} \mathrm{Hg})$ & $127 \pm 10$ & $138 \pm 15^{*}$ & $133 \pm 16$ \\
\hline $\mathrm{DBP}(\mathrm{mm} \mathrm{Hg})$ & $71 \pm 10$ & $79 \pm 11$ & $77 \pm 12$ \\
\hline Chronic kidney disease (\%) & 30 & 25 & 20 \\
\hline \multicolumn{4}{|l|}{ Medication } \\
\hline$\beta$-Blocker & 20 & 5 & 15 \\
\hline CCB (\%) & 40 & 60 & 40 \\
\hline Statin (\%) & 90 & 90 & 90 \\
\hline Nicorandil (\%) & 30 & 50 & 30 \\
\hline NG (\%) & 20 & 15 & 10 \\
\hline$\alpha-\mathrm{Gl}(\%)$ & 0 & 15 & 25 \\
\hline SU (\%) & 10 & 25 & 10 \\
\hline Thiazolidine (\%) & 0 & 10 & 5 \\
\hline Diuretics (\%) & 10 & 0 & 0 \\
\hline
\end{tabular}

Abbreviations: ACS, acute coronary syndrome; ARB, angiotensin II type 1 receptor blocker; BMI, body mass index; DBP, diastolic blood pressure; eGFR, estimated glomerular filtration rate; $\alpha$-GI, $\alpha$-glycosidase inhibitor; NG, nitroglycerin; SBP, systolic blood pressure; SU, sulfonyl urea. ${ }^{*} P<0.05$ vs. non-ARB. 
Angiographic characteristics at follow-up are also shown in Table 2. No significant differences were observed in the reference diameter, instent late loss or in-stent \% diameter stenosis between the non-ARB and ARB groups or the olmesartan and valsartan groups. In addition, in-stent restenosis rates in the non-ARB, olmesartan and valsartan groups were 20,15 and 10\%, respectively. Major adverse cardiac events were defined as cardiac death, Q wave MI and target lesion revascularization during the study period. There were no cardiac deaths or MI. Target lesion revascularization rates in the non-ARB, olmesartan

Table 2 Angiographic characteristics at baseline and follow-up

\begin{tabular}{|c|c|c|c|}
\hline & \multirow[b]{2}{*}{$\begin{array}{c}\text { Non-ARB } \\
(\mathrm{n}=10)\end{array}$} & \multicolumn{2}{|c|}{$A R B$} \\
\hline & & $\begin{array}{l}\text { Olmesartan } \\
(\mathrm{n}=20)\end{array}$ & $\begin{array}{l}\text { Valsartan } \\
(\mathrm{n}=20)\end{array}$ \\
\hline \multicolumn{4}{|l|}{ Baseline } \\
\hline \multicolumn{4}{|l|}{ Vessel disease } \\
\hline $1 / 2 / 3(\%)$ & 60/30/10 & $45 / 20 / 35$ & $55 / 15 / 30$ \\
\hline \multicolumn{4}{|l|}{ Target vessel } \\
\hline LAD/LCX/RCA (\%) & $80 / 10 / 10$ & $5 / 1 / 2$ & $53 / 21 / 26$ \\
\hline Complex (B2/C) lesion (\%) & 90 & 75 & 70 \\
\hline \multicolumn{4}{|l|}{ Stent type } \\
\hline BMS/DES $(n)$ & $30 / 70$ & $35 / 65$ & $45 / 55$ \\
\hline \multicolumn{4}{|l|}{ Pre-procedure } \\
\hline Lesion length (mm) & $21 \pm 11$ & $16 \pm 7$ & $20 \pm 7$ \\
\hline MLD (mm) & $0.64 \pm 0.45$ & $0.84 \pm 0.44$ & $0.86 \pm 0.42$ \\
\hline \multicolumn{4}{|l|}{ Post-procedure } \\
\hline Reference diameter (mm) & $2.67 \pm 0.64$ & $2.72 \pm 0.64$ & $2.83 \pm 0.53$ \\
\hline Mean stent diameter $(\mathrm{mm})$ & $3.04 \pm 0.54$ & $2.93 \pm 0.43$ & $2.93 \pm 0.41$ \\
\hline Mean stent length (mm) & $29.6 \pm 13.4$ & $23.1 \pm 9.8$ & $24.9 \pm 7.6$ \\
\hline In-stent \% DS (\%) & $12.1 \pm 5.3$ & $14.3 \pm 6.9$ & $17.9 \pm 10.4$ \\
\hline \multicolumn{4}{|l|}{ Follow-up } \\
\hline Reference diameter $(\mathrm{mm})$ & $2.94 \pm 0.71$ & $2.84 \pm 0.50$ & $2.89 \pm 0.49$ \\
\hline In-stent late loss (mm) & $0.47 \pm 0.61$ & $0.21 \pm 0.59$ & $0.26 \pm 0.80$ \\
\hline In-stent \% DS (\%) & $34.4 \pm 16.7$ & $26.8 \pm 10.6$ & $30.1 \pm 13.9$ \\
\hline
\end{tabular}

Abbreviations: BMS, bare metal stent; DES, drug eluting stent; LAD, left anterior descending artery: LCX, left circumflex coronary artery; MLD, minimal lumen diameter; DS, diameter stenosis; RCA, right coronary artery. and valsartan groups were 10,10 and 5\%, respectively, and there were no significant differences between the groups.

\section{BP and heart rate at baseline and at follow-up}

Blood pressure at baseline in the non-ARB group (127 \pm 10 / $71 \pm 10 \mathrm{~mm} \mathrm{Hg}$ ) was significantly lower than that in the ARB group (136 $\pm 15 / 78 \pm 11 \mathrm{~mm} \mathrm{Hg}$ ) (Figure 1). Although SBP and DBP in the olmesartan and valsartan groups decreased significantly from baseline to follow-up, there was no difference between the changes in SBP and DBP in the two groups. SBP and DBP at follow-up did not correlate with in-stent $\%$ diameter stenosis at follow-up $(y=10.5+0.038 \mathrm{x}$, $r=0.057, P=0.697$ and $y=27.6-0.18 \mathrm{x}, r=0.213, P=0.138$, respectively). Heart rate at baseline and follow-up were similar in the non-ARB, olmesartan and valsartan groups $(71 \pm 10$ per min and $72 \pm 11$ per min, $69 \pm 9$ per min and $70 \pm 10$ per min, $65 \pm 8$ per min and $71 \pm 8$ per min, respectively).

\section{Biochemical parameters in blood at baseline and at follow-up} Biochemical parameters in blood at baseline and at follow-up are shown in Table 3. All parameters, such as UA, HbAlc, adiponectin, MCP-1 and RANTES concentrations, at baseline and follow-up were similar between the non-ARB and ARB groups and between the olmesartan and valsartan groups.

Serum UA in the valsartan group increased significantly at followup. eGFR decreased significantly between baseline and follow-up in the ARB group (from $70 \pm 16 \mathrm{ml} \mathrm{min}^{-1}$ per $1.73 \mathrm{~m}^{2}$ at baseline to $65 \pm 16 \mathrm{ml} \mathrm{min}^{-1}$ per $1.73 \mathrm{~m}^{2}$ at follow-up), but not in the non-ARB group $\left(63 \pm 13 \mathrm{ml} \mathrm{min}^{-1}\right.$ per $1.73 \mathrm{~m}^{2}$ to $66 \pm 15 \mathrm{ml} \mathrm{min}^{-1}$ per $1.73 \mathrm{~m}^{2}$ ). In addition, eGFR decreased significantly in the valsartan group but not in the olmesartan group. The amount of contrast media used in stent implantation was similar between the groups (non-ARB group, $192 \pm 60 \mathrm{ml}$; olmesartan group, $169 \pm 50 \mathrm{ml}$; valsartan group, $164 \pm 44 \mathrm{ml}$ ). The levels of LDL-C at follow-up were significantly lower than those at baseline in the ARB group (both olmesartan and valsartan groups), but not in the non-ARB group.

\section{Changes in PTX3 and hs-CRP in blood}

Changes in PTX3 and hs-CRP in blood are shown in Figure 2. PTX3 and hs-CRP at baseline were similar between the non-ARB and ARB groups and between the olmesartan and valsartan groups. PTX3 and a

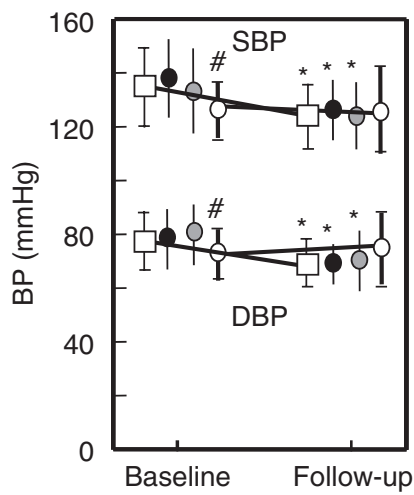

b

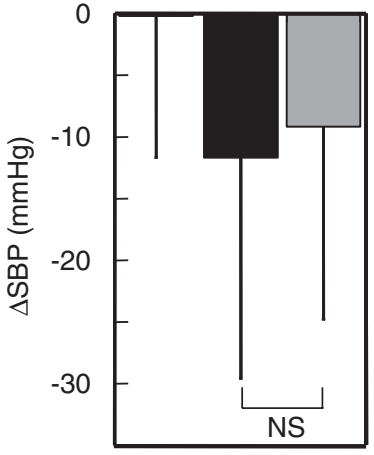

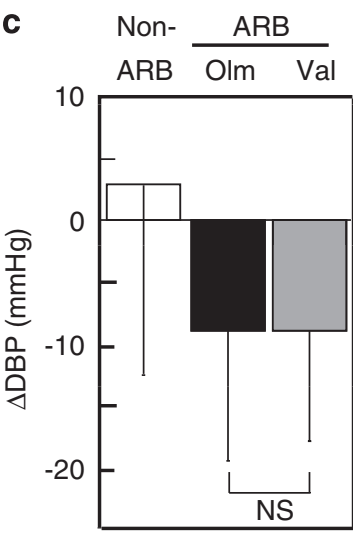

Figure 1 (a) Systolic and diastolic blood pressure (SBP and DBP) at baseline and follow-up in the non-ARB (open circles) and ARB (open squares) (olmesartan (closed circles) and valsartan (gray circles)) groups. (b and c) Changes in SBP or DBP in the non-ARB (open bars), olmesartan (closed bars) and valsartan (gray bars) groups. $\triangle \mathrm{BP}=\mathrm{BP}$ at follow-up minus $\mathrm{BP}$ at baseline. ${ }^{*} P<0.05$ vs. baseline. ${ }^{\#} P<0.05$ vs. baseline in the olmesartan and valsartan groups. NS, not significant. 
Table 3 Biochemical parameters in blood at baseline and follow-up

\begin{tabular}{|c|c|c|c|c|c|c|}
\hline & & & \multicolumn{4}{|c|}{$A R B$} \\
\hline & \multicolumn{2}{|c|}{ Non-ARB $(\mathrm{n}=10)$} & \multicolumn{2}{|c|}{ Olmesartan $(\mathrm{n}=20)$} & \multicolumn{2}{|c|}{ Valsartan $(\mathrm{n}=20)$} \\
\hline LDL-C (mg per $100 \mathrm{ml}$ ) & $117 \pm 32$ & $96 \pm 11$ & $118 \pm 28$ & $83 \pm 24^{*}$ & $128 \pm 37$ & $87 \pm 29 *$ \\
\hline TG (mg per $100 \mathrm{ml}$ ) & $134 \pm 63$ & $133 \pm 48$ & $161 \pm 93$ & $148 \pm 67$ & $163 \pm 87$ & $185 \pm 138$ \\
\hline $\mathrm{Na}\left(\mathrm{mEq} \mathrm{I}^{-1}\right)$ & $139 \pm 3$ & $140 \pm 3$ & $140 \pm 1$ & $141 \pm 1$ & $141 \pm 2$ & $142 \pm 1$ \\
\hline $\mathrm{K}\left(\mathrm{mEq} \mathrm{I}^{-1}\right)$ & $4.3 \pm 0.5$ & $4.3 \pm 0.5$ & $4.2 \pm 0.3$ & $4.3 \pm 0.3$ & $4.2 \pm 0.4$ & $4.3 \pm 0.4$ \\
\hline $\mathrm{HbA1c}(\%)$ & $6 \pm 1.3$ & $5.7 \pm 0.6$ & $6.9 \pm 1.8$ & $6.6 \pm 1.6$ & $6 \pm 1.1$ & $6.1 \pm 1$ \\
\hline eGFR $\left(\mathrm{ml} \mathrm{min}^{-1}\right.$ per $\left.1.73 \mathrm{~m}^{2}\right)$ & $63 \pm 13$ & $66 \pm 15$ & $72 \pm 14$ & $68 \pm 16$ & $68 \pm 19$ & $62 \pm 16^{*}$ \\
\hline Adiponectin (mg per $100 \mathrm{ml}$ ) & $3.7 \pm 2$ & $4.6 \pm 2.5$ & $4.5 \pm 2$ & $5 \pm 2.8$ & $4.1 \pm 1.9$ & $4.1 \pm 2.1$ \\
\hline MCP-1 $(\mathrm{mg}$ per $100 \mathrm{ml})$ & $178 \pm 200$ & $226 \pm 311$ & $142 \pm 75$ & $156 \pm 100$ & $138 \pm 41$ & $150 \pm 45$ \\
\hline
\end{tabular}

Abbreviations: eGFR, estimated glomerular filtration rate; HbAlc, hemoglobin Alc; HDL-C, high-density lipoprotein cholesterol; LDL-C, low-density lipoprotein cholesterol; MCP-1, monocyte chemotactic protein-1; UA, uric acid; RANTES, regulated upon activation, normal T-cell-expressed and secreted; TG, triglyceride.

${ }^{*} P<0.05$ vs. baseline.
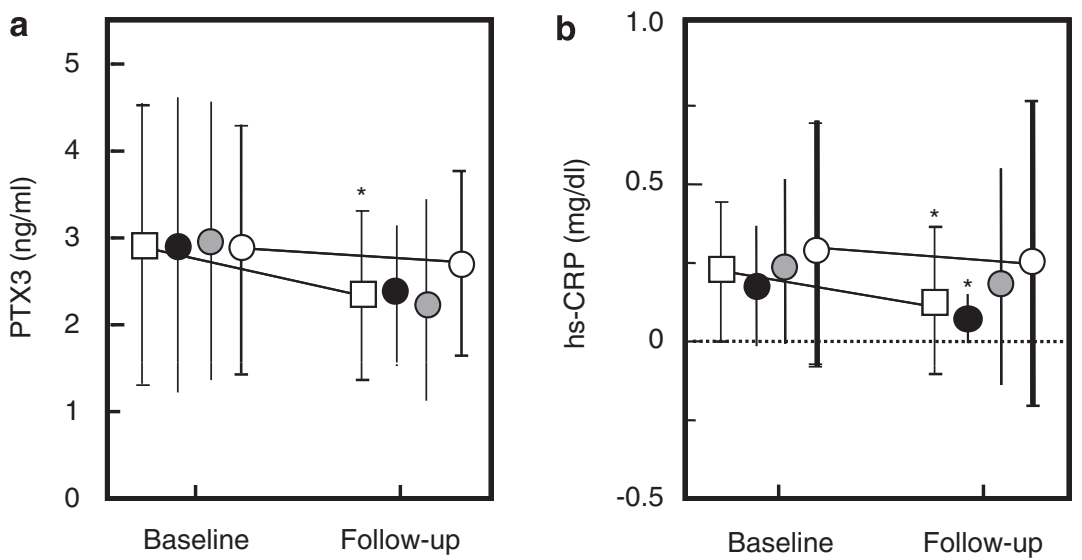

Figure 2 (a) Pentraxin 3 (PTX3) and (b) high-sensitive C-reactive protein (hs-CRP) at baseline and follow-up in the non-ARB (open circles) and ARB (open squares) (olmesartan (closed circles) and valsartan (gray circles)) groups. ${ }^{*} P<0.05$ vs. baseline.

hs-CRP decreased significantly at follow-up in the ARB group but not in the non-ARB group. In addition, hs-CRP in the olmesartan groups decreased significantly. Next, we analyzed the differences in PTX3 and CRP between the BMS and DES groups. The percentages of the types of stent were similar between the non-ARB and ARB groups and between the olmesartan and valsartan groups (Table 2). As the levels of PTX3 and CRP at baseline in the BMS group were significantly higher than those in the DES group (PTX3, $3.87 \pm 1.95 \mathrm{ng} \mathrm{ml}^{-1} v$. $2.46 \pm 1.12 \quad(P=0.025) ; \quad C R P, \quad 0.329 \pm 0.307 \mathrm{mg}$ per $100 \mathrm{ml}$ vs. $0.176 \pm 0.196(P=0.004))$, we analyzed the changes in PTX3 and hs-CRP from baseline to follow-up ( $\Delta=$ at follow-up minus at baseline). There were no significant changes in PTX3 or hs-CRP between the two groups $\left(\triangle \mathrm{PTX} 3,-1.04 \pm 2.32 \mathrm{ng} \mathrm{m}^{-1} v s\right.$. $-0.32 \pm 0.75(P=0.128) ; \Delta$ hs-CRP, $-0.056 \pm 0.348 \mathrm{mg}$ per $100 \mathrm{ml} v s$. $-0.091 \pm 0.182(P=0.647))$.

\section{DISCUSSION}

In this study, antihypertensive therapy with add-on low-dose ARB after successful stent implantation was safe and achieved the target BP. Moreover, olmesartan significantly decreased the level of hs-CRP, whereas valsartan increased serum UA.
With regard to BP-lowering, a J-curve phenomenon for the incidence of a primary outcome, such as all-cause death and non-fatal MI, is controversial. ${ }^{4-6}$ However, a lower DBP could compromise blood flow to target organs, thus impairing coronary perfusion and causing cardiac ischemia. The DBP level at the bottom of the J-curve was $70-80 \mathrm{~mm} \mathrm{Hg}^{5}$ and an SBP above $120 \mathrm{~mm} \mathrm{Hg}$ was positively associated with a mortality risk. ${ }^{15}$ As the BP levels in the non-ARB and ARB groups at follow-up were equal and about $125 / 70 \mathrm{~mm} \mathrm{Hg}$ in this study, the BP levels are around the bottom of the J-curve and suitable for preserving coronary blood flow. Our antihypertensive therapy with add-on low-dose ARB after successful stent implantation also achieved the target BP $(<130 / 80 \mathrm{~mm} \mathrm{Hg})$. In addition, in-stent \% diameter stenosis was not associated with BP reduction at follow-up in this study. Although the incidence of major adverse cardiac events was low and clear differences could not be seen, antihypertensive therapy with add-on ARB did not induce a severe BP reduction and showed optimal BP.

C-reactive protein plays a pathological role in the progression of $\mathrm{CAD}$ and is a well-established predictor of future cardiovascular events. ${ }^{16}$ ARBs have been shown to reduce the serum or plasma CRP concentration. Olmesartan significantly reduced serum CRP in 
patients with essential HT by as early as week 6 of therapy in a prospective double-blind multicenter study. ${ }^{8}$ Valsartan also reduced plasma levels of CRP in hypertensive patients with left ventricular hypertrophy ${ }^{17}$ and in hypertensive patients with other cardiovascular risk factors. ${ }^{18}$ In this study, olmesartan but not valsartan significantly decreased the serum level of CRP. Although there are many CRPlowering agents such as statins, $\beta$-blocker, calcium channel blockers and thiazolidine ${ }^{16}$ there were no significant differences in the percentage of medications between the olmesartan and valsartan groups. Although we do not know precisely why valsartan did not reduce serum CRP in this study, two possible explanations are that the dose of valsartan was relatively low and the characteristics of the participants were different from those in previous reports. ${ }^{17,18}$ In addition, the ARB group showed a significant reduction of PTX3 in blood in this study. The relative increase in PTX3 at $24 \mathrm{~h}$ after coronary stenting was the most powerful predictor of late lumen loss. ${ }^{19}$ As PTX3 was significantly higher in the unstable angina pectoris group compared with the control group, ${ }^{20}$ and because macrophages expressed PTX3 in advanced atherosclerotic lesions, and PTX3-positive neutrophils infiltrated into coronary atherosclerotic plaques removed from patients with acute $\mathrm{MI}{ }^{7} \mathrm{ARB}$ might have a critical role in antiatherogenesis and prevent cardiac events through suppression of PTX3.

There were no significant changes in PTX3 or hs-CRP between the BMS and DES groups in this study. DES showed significantly lower plasma CRP levels after coronary stenting compared with BMS. ${ }^{21}$ In addition, patients who underwent DES implantation showed less augmentation of early inflammatory markers after stenting than did patients treated with BMS. ${ }^{22}$ We reported earlier that there was no significant difference in hs-CRP between BMS and DES during a 6-8 month period. ${ }^{23}$ On the other hand, a DES group tended to show higher systemic levels of all proinflammatory markers compared with a BMS group. ${ }^{24}$ Thus, the cause of this discrepancy is unclear and more precise data will be needed to resolve this issue.

Over the past decade, the efficacies of ARBs have been compared and differences have been observed with regard to the lowering of BP. For example, ambulatory BP was significantly greater for patients who received olmesartan than for those who received losartan or valsartan. ${ }^{25}$ Brunner et al. ${ }^{25}$ reported that greater proportions of olmesartan-treated $\left(20 \mathrm{mg} \mathrm{day}^{-1}\right)$ patients achieved goals of $<135 / 80 \mathrm{~mm} \mathrm{Hg}$ over $24 \mathrm{~h}$ compared with those treated with candesartan $8 \mathrm{mg} \mathrm{day}^{-1}$. Although the olmesartan and valsartan groups showed significant reductions in BP from baseline to follow-up, there was no difference in the changes in BP between the two groups. There are two main reasons why olmesartan did not significantly lower BP compared with valsartan. First, BP levels at baseline in both the olmesartan and valsartan groups were not particularly high (138/79 and 133/ $77 \mathrm{~mm} \mathrm{Hg}$, respectively). Second, the doses of olmesartan and valsar$\tan \left(14 \pm 8\right.$ and $60 \pm 23 \mathrm{mg} \mathrm{day}^{-1}$, respectively) were not so high. If patients show higher basal BP levels and receive higher doses of ARBs, it may be easy to see differences in the BP-lowering effects of olmesartan and valsartan.

In the ARB group, eGFR at baseline decreased significantly compared with that at follow-up. GFR generally decreases at $2 \mathrm{ml} \mathrm{min}^{-1}$ year $^{-1}$ with aging. ${ }^{26}$ In the ARB group, GFR decreased at more than $2 \mathrm{ml} \mathrm{min}^{-1}$ year $^{-1}$. Although the change in GFR from baseline to follow-up was about $5 \mathrm{ml} \mathrm{min}^{-1}$ per $1.73 \mathrm{~m}^{2}$, it is common for GFR to decrease shortly after the initiation of treatment with ARB. This response is functional in nature and should be expected on the basis of renal physiology (adaptive effect against reduction in glomerular BP) and its dependence on the renin-angiotensin system to maintain GFR. As an early elevation in serum creatinine is associated with improved long-term renal outcomes, the slight fall in the GFR in this study should not cause concern. Another important issue is that several ARBs have been reported to increase the serum UA level, whereas losartan was associated with a decrease in serum UA levels. ${ }^{27}$ Different ARBs seem to have different effects (cis-inhibition, trans-stimulation or both) on UA transport through the renal UA transporter. ${ }^{28}$ Although valsartan did not induce an increase in UA, ${ }^{28}$ our data indicated that valsartan, but not olmesartan, increased serum UA. Although we cannot explain this contradiction clearly at this stage, olmesartan did not have a negative influence on the serum UA level. As the serum UA level is regulated by eGFR, and because eGFR in the valsartan group decreased significantly at follow-up compared with baseline, it is possible that an increase in serum UA in the valsartan group may reflect a decrease in eGFR. As there were no serious side effects in the ARB group, the use of ARBs was safe and olmesartan, in particular, may be more useful.

The ARB group (olmesartan and valsartan groups), but not the non-ARB group, showed a significant reduction of LDL-C levels, whereas there was no difference in the percentage of statin treatment between the non-ARB and ARB groups or between the olmesartan and valsartan groups. ARB has been shown to affect lipid metabolism and to decrease total cholesterol and LDL-C in patients with HT. ${ }^{29,30}$ It is possible that the lipid-lowering effects of ARB are due to many different mechanisms. Ang II stimulation of macrophage cholesterol biosynthesis is related to its interaction with the $\mathrm{AT}_{1}$ receptor, followed by the stimulation of macrophage HMG-CoA reductase gene expression. ${ }^{31}$ Losartan abolished the Ang II-induced upregulation of proteoglycans with enhanced LDL-binding properties. ${ }^{32}$ Some ARBs activate peroxisome proliferator-activated receptor- $\gamma$, which regulates lipid metabolism. ${ }^{33}$ However, further studies will be needed to establish a relation between ARBs and improved lipid metabolism.

\section{Study limitations}

The main limitation of this study is the small number of patients in a single center study design. The effect of BP-lowering by ARBs should be confirmed in a large randomized multicenter study.

In conclusion, antihypertensive therapy with add-on low-dose ARB after successful stent implantation was safe and achieved the target BP, and olmesartan in particular induced an anti-inflammatory effect. This strategy may make it possible to avoid coronary events because of higher BP.

\section{CONFLICT OF INTEREST}

The authors declare no conflict of interest.

1 De Gasparo M, Catt K, Inagami T, Wright JW, Unger T. International Union of Pharmacology. XXIII. The angiotensin II receptors. Pharmacol Rev 2000; 52: 415-472.

2 Miura S, Saku K, Karnik SS. Molecular analysis of the structure and function of the angiotensin II type 1 receptor. Hypertens Res 2003; 26: 937-943.

3 Japanese Society of Hypertension. Committee for Guidelines for the management of hypertension (JSH 2009). Hypertens Res 2009; 32: 11-23.

4 Cruickshank J. The J-curve in hypertension. Curr Cardiol Rep 2003; 5: 441-452.

5 Messerli FH, Mancia G, Conti CR, Hewkin AC, Kupfer S, Champion A, Kolloch R, Benetos A, Pepine CJ. Dogma disputed: can aggressively lowering blood pressure in hypertensive patients with coronary artery disease be dangerous? Ann Intern Med 2006; 144: 884-893.

6 Arima H, Tanizaki Y, Kiyohara Y, Tsuchihashi T, Kato I, Kubo M, Tanaka K, Ohkubo K, Nakamura H, Abe I, Fujishima M, lida M. Validity of the JNC VI recommendations for the management of hypertension in a general population of Japanese elderly: the Hisayama study. Arch Intern Med 2003; 163: 361-366. 
7 Savchenko A, Imamura M, Ohashi R, Jiang S, Kawasaki T, Hasegawa G, Emura I, Iwanari H, Sagara M, Tanaka T, Hamakubo T, Kodama T, Naito M. Expression of pentraxin 3 (PTX3) in human atherosclerotic lesions. J Pathol 2008; 215: 48-55.

8 Fliser D, Buchholz K, Haller H, EUropean Trial on Olmesartan and Pravastatin in Inflammation and Atherosclerosis (EUTOPIA) Investigators. Antiinflammatory effects of angiotensin II subtype 1 receptor blockade in hypertensive patients with microinflammation. Circulation 2004; 110: 1103-1107.

9 Graninger M, Reiter R, Drucker C, Minar E, Jilma B. Angiotensin receptor blockade decreases markers of vascular inflammation. J Cardiovasc Pharmacol 2004; 44: 335-339.

10 Usui M, Egashira K, Tomita H, Koyanagi M, Katoh M, Shimokawa H, Takeya M, Yoshimura T, Matsushima K, Takeshita A. Important role of local angiotensin II activity mediated via type 1 receptor in the pathogenesis of cardiovascular inflammatory changes induced by chronic blockade of nitric oxide synthesis in rats. Circulation 2000; 101: 305-310.

11 Nomura S, Shouzu A, Omoto S, Nishikawa M, Fukuhara S, Iwasaka T. Effect of valsartan on monocyte/endothelial cell activation markers and adiponectin in hypertensive patients with type 2 diabetes mellitus. Thromb Res 2006; 117: 385-392.

12 Peters S, Gotting B, Trummel M, Rust H, Brattstrom A. Valsartan for prevention of restenosis after stenting of type B2/C lesions: the VAL-PREST trial. J Invasive Cardiol 2001; 13: 93-97.

13 Smith DH, Dubiel R, Jones M. Use of 24-hour ambulatory blood pressure monitoring to assess antihypertensive efficacy: a comparison of olmesartan medoxomil, losartan potassium, valsartan, and irbesartan. Am J Cardiovasc Drugs 2005; 5: 41-50.

14 Imai E, Horio M, Iseki K, Yamagata K, Watanabe T, Hara S, Ura N, Kiyohara Y, Hirakata H, Moriyama T, Ando Y, Nitta K, Inaguma D, Narita I, Iso H, Wakai K, Yasuda $Y$, Tsukamoto $\mathrm{Y}$, Ito $\mathrm{S}$, Makino H, Hishida A, Matsuo S. Prevalence of chronic kidney disease (CKD) in the Japanese general population predicted by the MDRD equation modified by a Japanese coefficient. Clin Exp Nephrol 2007; 11: 156-163.

15 Greenberg JA. Removing confounders from the relationship between mortality risk and systolic blood pressure at low and moderately increased systolic blood pressure. J Hypertens 2003; 21: 49-56.

16 Prasado K. C-reactive protein (CRP)-lowering agents. Cardiovasc Drug Rev 2006; 24: 33-50.

17 Yasunari K, Maeda K, Watanabe T, Nakamura M, Yoshikawa J, Asada A. Comparative effects of valsartan versus amlodipine on left ventricular mass and reactive oxygen species formation by monocytes in hypertensive patients with left ventricular hypertrophy. J Am Coll Cardiol 2004; 43: 2116-2123.

18 Ruilope LM, Malacco E, Khder Y, Kandra A, Bönner G, Heintz D. Efficacy and tolerability of combination therapy with valsartan plus hydrochlorothiazide compared with amlodipine monotherapy in hypertensive patients with other cardiovascular risk factors: the VAST study. Clin Ther 2005; 27: 578-587.

19 Kotooka N, Inoue T, Fujimatsu D, Morooka T, Hashimoto S, Hikichi Y, Uchida T, Sugiyama A, Node K. Pentraxin3 is a novel marker for stent-induced inflammation and neointimal thickening. Atherosclerosis 2008; 197: 368-374.

20 Inoue K, Sugiyama A, Reid PC, Ito Y, Miyauchi K, Mukai S, Sagara M, Miyamoto K, Satoh H, Kohno I, Kurata T, Ota H, Mantovani A, Hamakubo T, Daida H, Kodama T.
Establishment of a high sensitivity plasma assay for human pentraxin3 as a marker for unstable angina pectoris. Arterioscler Thromb Vasc Biol 2007; 27: 161-167.

21 Kim JY, Ko YG, Shim CY, Park S, Hwang KC, Choi D, Jang Y, Chung N, Shim WH, Cho SY. Comparison of effects of drug-eluting stents versus bare metal stents on plasma C-reactive protein levels. Am J Cardiol 2005; 96: 1384-1388.

22 Li JJ, Qin XW, Yang XC, Li ZC, Zeng HS, Xu B, Gao Z, Wu YJ, Zhang X, Zhang CY. Randomized comparison of early inflammatory response after sirolimus-eluting stent vs bare metal stent implantation in native coronary lesions. Clin Chim Acta 2008; 396: 38-42.

23 Sako H, Miura S, Iwata A, Nishikawa H, Kawamura A, Matsuo K, Shirai K, Saku K. Changes in CCR2 chemokine receptor expression and plasma MCP-1 concentration after the implantation of bare metal stents versus sirolimus-eluting stents in patients with stable angina. Intern Med 2008; 47: 7-13.

24 Rebeiz AG, Zoghbi E, Harb R, Youhanna S, Skouri HN, Dimassi A, Abou-Nader G, Nasrallah A, Sawaya J, Gharzuddine W, Alam S. Comparison of the systemic levels of inflammatory markers after percutaneous coronary intervention with bare metal versus sirolimus-eluting stents. J Interv Cardiol 2009; 22: 169-174.

25 Brunner HR, Arakawa K. Antihypertensive efficacy of olmesartan medoxomil and candesartan cilexetil in achieving 24-hour blood pressure reductions and ambulatory blood pressure goals. Clin Drug Investig 2006; 26: 185-193.

26 Bakris GL, Williams M, Dworkin L, Elliott WJ, Epstein M, Toto R, Tuttle K, Douglas J, Hsueh W, Sowers J. Preserving renal function in adults with hypertension and diabetes: a consensus approach. National Kidney Foundation Hypertension and Diabetes Executive Committees Working Group. Am J Kidney Dis 2000; 36: 646-661.

27 Elliott WJ, Calhoun DA, DeLucca PT, Gazdick LP, Kerns DE, Zeldin RK. Losartan versus valsartan in the treatment of patients with mild to moderate essential hypertension: data from a multicenter, randomized, double-blind, 12-week trial. Clin Ther 2001; 23: 1166-1179.

28 Iwanaga T, Sato M, Maeda T, Ogihara T, Tamai I. Concentration-dependent mode of interaction of angiotensin II receptor blockers with uric acid transporter. J Pharmacol Exp Ther 2007; 320: 211-217.

29 Derosa G, Ragonesi PD, Mugellini A, Ciccarelli L, Fogari R. Effects of telmisartan compared with eprosartan on blood pressure control, glucose metabolism and lipid profile in hypertensive, type 2 diabetic patients: a randomized, double-blind, placebocontrolled 12-month study. Hypertens Res 2004; 27: 457-464.

30 Hanefeld M, Abletshauser $\mathrm{C}$. Effect of the angiotensin II receptor antagonist valsartan on lipid profile and glucose metabolism in patients with hypertension. J Int Med Res 2001; 29: 270-279.

31 Keidar S, Attias J, Heinrich R, Coleman R, Aviram M. Angiotensin II atherogenicity in apolipoprotein $\mathrm{E}$ deficient mice is associated with increased cellular cholesterol biosynthesis. Atherosclerosis 1999; 146: 249-257.

32 Figueroa JE, Vijayagopal P. Angiotensin II stimulates synthesis of vascular smooth muscle cell proteoglycans with enhanced low density lipoprotein binding properties. Atherosclerosis 2002; 162: 261-268.

33 Schupp M, Janke J, Clasen R, Unger T, Kintscher U. Angiotensin type 1 receptor blockers induce peroxisome proliferator-activated receptor-gamma activity. Circulation 2004; 109: 2054-2057. 